\title{
A COLOCAÇÃO DO ENGENHEIRO PERANTE O MERCADO DE TRABALHO
}

\author{
Alexandre FERNANDES ${ }^{1}$ \\ André BUGARELI ${ }^{2}$ \\ Barbara Brunner Pires SANTOS ${ }^{3}$ \\ Euler Lucio SOARES ${ }^{4}$ \\ Fernanda Aparecida da SILVA ${ }^{5}$ \\ Gustavo ESTEVAM ${ }^{6}$ \\ Simone de Fátima SANTOS ${ }^{7}$ \\ Suelem Cristina Do Carmo $\mathrm{CRUZ}^{8}$ \\ Eloisa Márcia da Silva TAMPIERI ${ }^{9}$
}

\begin{abstract}
${ }^{1}$ Estudante de Engenharia de Produção. Centro Universitário de Belo Horizonte - UNIBH. mineirinhosgrill@yahoo.com.br

${ }^{2}$ Estudante de Engenharia de Produção. Centro Universitário de Belo Horizonte - UNIBH. andrebugareli@ gmail.com ${ }^{3}$ Estudante de Engenharia de Produção. Centro Universitário de Belo Horizonte - UNIBH. barbara.brunnerps@gmail.com

${ }^{4}$ Estudante de Engenharia de Produção. Centro Universitário de Belo Horizonte - UNIBH. euler8443@ bol.com.br

${ }^{5}$ Estudante de Engenharia de Produção. Centro Universitário de Belo Horizonte - UNIBH. fernandasilva_1994@hotmail.com

${ }^{6}$ Estudante de Engenharia de Produção. Centro Universitário de Belo Horizonte - UNIBH. geds_bh@ @otmail.com

${ }^{7}$ Estudante de Engenharia de Produção. Centro Universitário de Belo Horizonte - UNIBH. simonesantos1101@yahoo.com.br

${ }^{8}$ Estudante de Engenharia de Produção. Centro Universitário de Belo Horizonte - UNIBH. suelemehigor@ hotmail.com

${ }^{9}$ Professora Orientadora, Docente do Curso Engenharia de Produção. Centro Universitário de Belo Horizonte UNIBH. eloisa.silva@ prof.unibh.br9
\end{abstract}

Recebido em: 10/06/2014 - Aprovado em: 20/09/2014 - Disponibilizado em: 15/12/2014

Resumo: As empresas preferem contratar engenheiros em cargos inferiores para terem menos gastos e a mesma qualidade de serviço do engenheiro profissional. Assim, muitos estudantes de engenharia possuem dúvidas de como ingressar no mercado de trabalho após a formação. Então, foi analisado o quê o engenheiro precisa para ser bem sucedido e diferenciado no mercado de trabalho, explorando dados referentes à colocação de um engenheiro na empresa. $\mathrm{O}$ engenheiro de produção pode atuar em varias áreas no mercado, possui uma diversidade nos cursos de pósgraduação e especialização, podendo assim melhorar o seu currículo e divulgá-lo em alguns sites de Recursos Humanos que são divulgados na internet, lembrando que quanto mais experiência e qualificação tiverem em sua área, mais rápido será o seu sucesso como engenheiro.

Palavras-chave: Colocação no Mercado. Engenheiro de Produção. Mercado de Trabalho. Curriculos de Sucesso. Desafios enfrentados por Engenheiros.

\section{PLACEMENT ENGINEER BEFORE THE LABOUR MARKET}

\begin{abstract}
Companies prefer to hire engineers with lower positions to have less spending and the same quality of service of a professional engineer. So much engineering student has questions on how to enter the job market after forming, so it was analyzed that the engineer needs to be successful and differentiated in the labor market, using data relating to the placing of an engineer in the company. The production engineer can work in varies areas in the market, has a variety of courses in graduate and specialization, which may improve your resume and disseminates it in some sites of Human Resources which are advertised on the Internet, noting that the more have experience and expertise in their area, the faster your success as an engineer.
\end{abstract}

Keywords: Placing on the Market. Production Engineer. Labour market. Success Curriculum. Challenges faced by engineers. 


\section{INTRODUÇÃ̃O}

A Engenharia de produção é uma profissão que gerencia recursos humanos, financeiros $\mathrm{e}$ materiais, sendo o profissional requisitado responsável por definir funções, planejar escalas de trabalho definindo a melhor forma de integrar mão-de-obra, equipamentos e matéria-prima, e para realizar estas funções muitas empresas contratam profissionais de engenharia como gerentes, supervisores, analistas.

Para as empresas esta forma de contratação tem um custo menor, pois se estas optarem pela contratação de engenheiro o salário do mesmo gira em torno de 5.000 a 8.000 mil reaisไmês. Já um gerente ou analista realizaria as funções deste profissional, atendendo as exigências da empresa recebendo a metade do salário, ficando muitos recém-formados deslocados. Através da preocupação com a realidade vivenciada no mercado de trabalho, objetiva-se descobrir caminhos que possam levar um profissional a uma condição diferenciada, ou seja, um profissional bem sucedido, analisando o perfil de engenheiros renomados na mídia e no mercado conhecendo suas histórias.

Considerando a importância de situar-se no mercado de trabalho pós-formado questiona-se diploma na mão o que fazer?

Como objetivo geral deste trabalho busca analisar o perfil de engenheiros bem sucedidos, renomados na mídia e mercado. Sendo os objetivos específicos explorar dados referentes a colocação de um engenheiro na empresa, estudar dados em comum entre os currículos de gestores bem sucedidos, apresentar desafios enfrentados por engenheiros recém-formados;

A relevância deste estudo se justifica pelos seguintes motivos: a necessidade de nortear os futuros engenheiros, a possibilidade de inserção deles no mercado de trabalho, a identificação da procura de profissionais capacitados, a importância de coloca-los a frente e possíveis desafios.

\section{Desafios Enfrentados Por Engenheiros RECÉM - FORMADOS}

\subsection{O Mercado Aquecido Sente Falta de Profissionais}

Como abordado por Luiz Wever (2005), "Percebemos que os engenheiros, cada vez mais, têm seguido outros caminhos que não $\mathrm{o}$ da engenharia", o profissional formado em engenharia se torna mão de obra qualificada e utilizada em outros setores das grandes empresas.

A profissão mais comum entre aqueles que ocupam o topo da pirâmide das empresas não é Administração de Empresas, como todos instintivamente pensariam.

Para entender e lidar com os desafios lógicos e abstratos do mercado, nada melhor que um engenheiro. De acordo com uma pesquisa realizada pela Heidrick \& Struggles (2005), “os 
engenheiros ocupam hoje $49 \%$ das cadeiras presidenciais de empresas do País".

A primeira pista para explicar por que o Brasil ainda sofre com a falta de engenheiros, ao contrário do diagnóstico da carência dessa mão de obra qualificada pode levar a supor, não faltam vagas em escolas de engenharia, que poderiam estar formando o número de profissionais de que o país tanto necessita, como dito por Danilo Oliveira (2010), que aos 25 anos, se formaria em engenharia civil, "da minha turma de 50 alunos, apenas 19 se formaram", diz Oliveira, que atua como analista de negócios do Itaú.

Segundo o professor José Roberto Cardoso (2013), somando todas as faculdades, há cerca de 300 mil vagas no primeiro ano. Potencialmente, se nos próximos cinco anos o Brasil mantivesse a entrada de alunos nesse patamar, em 2018 haveria quase 1,5 milhões de alunos estudando engenharia. (CARDOSO, 2013)

Vagas disponíveis e matricula efetuada, no entanto não significa que necessariamente todos os alunos se formarão, com uma conta simples percebe-se que a evasão no curso de engenharia supera os $50 \%$.

De acordo com o ministro da Educação, Aloizio Mercadante (2013), em 2007, quase 114 mil alunos ingressou em cursos de engenharia. Cinco anos depois, apenas 45 mil deles receberam o diploma. Para o governo federal, esse quadro já está mudando. Estamos incentivando o ensino da matemática no ensino médio um dos caminhos é a olimpíada de matemática, com 20 milhões de alunos. Investir no ensino médio é imprescindível. As escolas de engenharia estão gastando o primeiro ano para ensinar fundamentos de matemática, física e química, diz Aluízio de Barros Fagundes (2013), presidente do Instituto de Engenharia. (PINHEIRO, 2013).

Na década de 1970, o Brasil atraiu um elevado número de engenheiros do exterior, quando as montadoras de automóveis estavam a pleno vapor.

O momento atual é propício para um novo ciclo de imigrações, apesar de o tema ser visto com desconfiança pelas entidades do setor. "Importar mão de obra é apenas um paliativo", diz Sergio Watanabe (2013), presidente do Sindicato da Indústria da Construção Civil de São Paulo (Sinduscon-SP). "Quando a situação econômica melhorar lá fora, esses profissionais podem simplesmente deixar o Brasil”. Outra preocupação é a dificuldade com o idioma brasileiro. "Tem engenheiro sobrando na China e na Índia, mas o idioma inviabiliza a importação", diz Aluizio Fagundes (2013). Não faltam motivos atraentes para engenheiros optarem pelo Brasil, além das grandes crises econômicas no exterior, os estrangeiros estão de olho nas altas remunerações oferecidas a engenheiros no país.

Dados mostram que os salários continuam num patamar elevado, após uma série de reajustes entre 2008 e 2010. “A construção civil paga tão bem quanto qualquer área, incluindo salários e benefícios", disse Alexandre Pacheco (2013), gerente da Hay Group, em São Paulo. 
Um salário-base do engenheiro recém-formado, ou engenheiro júnior, supera os $\mathrm{R} \$ 5.500,00$ reais. Para a categoria sênior, a remuneração chega, em média, a R\$ 9 mil, sem contar bônus e benefícios. Mas quando trocam o capacete pelo terno e gravata, para assumir cargos de gestão, o céu é o limite, dados estes identificados em um levantamento. Alexandre Pacheco, da Hay Group, afirma

"não tenho dúvidas de que os ventos estão mais favoráveis do que nunca para quem trilhou essa carreira se o Brasil voltar a crescer $3,5 \%$ ao ano, não faltará espaço para os jovens engenheiros". (Alexandre Pacheco 2013)

Para quem viveu as turbulências da engenharia na década de 1990 e no início dos anos 2000, como o engenheiro Arthur Cecílio, o quadro atual é um paraíso. "Hoje, ninguém mais pede uma Picape no currículo", diz Cecílio (2013). Para as empresas, a falta de mão de obra representa um custo. Se os cálculos do governo e das entidades privadas estiverem corretos, a fábrica de engenheiros estará operando a pleno vapor em até cinco anos, estabilizando entre oferta e demanda a relação.
São as pessoas que podem propiciar um diferencial nos produtos e serviços oferecidos às empresas e é através dos recursos humanos que as empresas serão capazes de colocar no mercado produtos e serviços suficientemente competitivos. Com a observação desse fato, surge a necessidade de estudos mais detalhados sobre recursos humanos; por ser uma área muito abrangente, o enfoque neste trabalho está no recrutamento e seleção, pois, através desses processos que os candidatos ingressam nas empresas e se tornam funcionários.

Faz-se necessário avaliar as formas de recrutar e selecionar pessoas, visto que os Recursos Humanos são fatores importantíssimos para o funcionamento de qualquer organização. Sua importância pode variar de acordo com o grau de automatização dos processos.

É importante observar também os impactos de um recrutamento e seleção feitos de forma errada, analisar os custos e a perda de tempo na substituição de um empregado ou até mesmo os prejuízos causados pelo mesmo, que pode não realizar suas tarefas de forma produtiva e também a insatisfação do funcionário trabalhando em um local onde o mesmo não está apto.

\subsection{Currículos de SuCESSO}

A plataforma Lattes foi criada e mantida pelo CNPq - Conselho Nacional de Desenvolvimento Científico e Tecnológico - para facilitar as ações de planejamento, gestão e operacionalização do 
fomento à pesquisa. Funciona com uma integra as bases de dados de currículos, grupos de pesquisa e instituições, em um único sistema de informações sendo atuado no Brasil. O currículo Lattes permite que as instituições tenham uma fácil visão curricular de engenheiros como: avaliar o seu trabalho como pesquisado; diagnosticar o perfil do pesquisador com outros dentro de sua área e atuação. Para o pesquisador é importante a participação de projetos e para as avaliações de produção cientifica. Possui diversos tipos de ferramentas disponíveis para a visualização do currículo Lattes, sendo elas. LattesX, scriplattes e transformador XML Lattes.

De acordo com reportagem.

Muitos engenheiros depois de formados ocupam cargos de gerentes, gestores e até mesmo de empresários. E o que esses engenheiros têm em comum é que a maioria são bilíngues, possuem pósgraduação em gestão de negocio, no mínimo 5 anos de experiência no mercado de trabalho. Temos como exemplo o gerente executivo da área de qualidade na empresa Volkswagen, que é formado em engenharia de produção e está há quase 20 anos na empresa. (ABRIL, 2013)

O salário de engenheiro está na base de sete salários mínimos ao mês, por ser um valor auto as empresas preferem contratar os engenheiros para os cargos de gerência e coordenação, assim irá ter menos despesas com o funcionário e todos os requisitos de um engenheiro.
As empresas procuram engenheiros que tenham competência em: inovar, focar no cliente organizar, cooperar, colaborar, empreender, criar, delegar, liderar equipes, relacionar-se com outras pessoas, negociar, resolver problemas, visualizar e analisar o sistema como um todo, gerir equipes técnicas, gerenciar recursos, lidar com situações novas, raciocinar rapidamente, analisar custos, verificar tendências, trabalhar sem supervisão, isso faz com o engenheiro seja de sucesso em sua área e empresa que atuar.

Usando como exemplo o currículo bem-sucedido do engenheiro Leonardo Bantes Arnt.

Aos 23 anos, Leonardo Bantes Arnt já é um profissional bem sucedido. Formado na Universidade Federal do Rio de Janeiro em 2009, o engenheiro de computação é um dos sócios da Inoa Sistemas, especializada em algorithmic trading (comercio algoritmico). $\mathrm{Na}$ empresa sua tarefa é aprimorar esse complexo sistema de execução de ordens de negociação baseados em algoritmos predefinidos pelo usuário. Apesar da pouca idade Leonardo desconhece o que desemprego e já é dono do seu destino. (ARTIGO ESTUDO SOBRE O MERCADO DO ENGENHEIRO NO BRASIL)

\section{Metodologia}

Este estudo iniciou-se com uma pesquisa bibliográfica, ou seja, um estudo de fontes 
secundárias sobre 0 tema colocação do Engenheiro perante o mercado de trabalho, com o objetivo de despertar nos jovens o interesse por uma área de sucesso, de grandes conquistas e satisfação no mercado.

Em relação ao método de estudo o presente trabalho é uma pesquisa descritiva. São inúmeros os estudos que podem ser classificados sob este título e uma de suas características mais significativas está na utilização de coleta de dados, tais como currículos de profissionais bem sucedidos e a observação sistemática.

Serão analisados os contextos que influenciam na opinião dos alunos do curso de engenharias com relação ao diploma na mão, mas o que fazer e outra parte, tendo em vista que serão identificadas respostas de muito profissionais para transformar os dados coletados em índices que serão apresentados em nosso trabalho.

\section{Resultado}

As classificações adotadas pela ABEPRO, (Associação Brasileira de Engenharia De Produção), as áreas típicas da Engenharia de produção são: Gerência da Produção, Qualidade, Gestão Econômica, Ergonomia e Segurança do Trabalho, Engenharia do Produto, Pesquisa Operacional, Estratégias e Organizações, Gestão da Tecnologia, Sistemas de Informação e Gestão Ambiental.

De acordo com as diretrizes da ABEPRO, torna-se claro que a Engenharia de Produção é, essencialmente, uma engenharia eclética e generalista, diferente das outras modalidades por não ter uma base tecnológica tradicional. Porém, a Engenharia de Produção tem uma base consistente que é a formação sistêmica que capacita o engenheiro a articular a base técnica, que suporta a produção, com as demais funções da organização, como recursos humanos, finanças e mercado.

Expectativa do mercado profissional, o componente importante no projeto do curso é a análise das necessidades da sociedade e do mercado. É importante formar um profissional capaz de operacionalizar os conhecimentos adquiridos, mas também capaz de deter uma formação profissional continuada ao longo de sua carreira, a fim de atender às expectativas das empresas.

Os desafios para o recém-formado é o fato de não ter vivido a experiência, e a situação que deixa o estudante preocupado e de adquirido a bagagem do seu exercício profissional no dia-a-dia. Como todo recém-formado de qualquer área seja Engenharia ou outra qualquer, os desafios são grandes, porém com futuros bons resultados se podem trilhar pelo caminho certo.

O desafio maior é você, além da faculdade, ter um pouco de experiência prática na área escolhida, comprovada em carteira, é um diferencial, pois hoje apesar do mercado oferecer boas oportunidades, também temos que saber onde e como nos lançar nele, iniciando com um currículo bem elaborado. 
Após várias pesquisas foi possível obter uma amostra demandada considerada representativa dos cursos de Engenharia.

O gráfico seguinte mostra o crescimento experimentado pelas 10 principais modalidades de Engenharia no período de 2001 a 2011 em termos de número de cursos oferecidos. A Engenharia de Produção é a modalidade que detém a maior quantidade de cursos na atualidade, mesmo sendo este um curso recente quando comparado com as Engenharias Tradicionais.

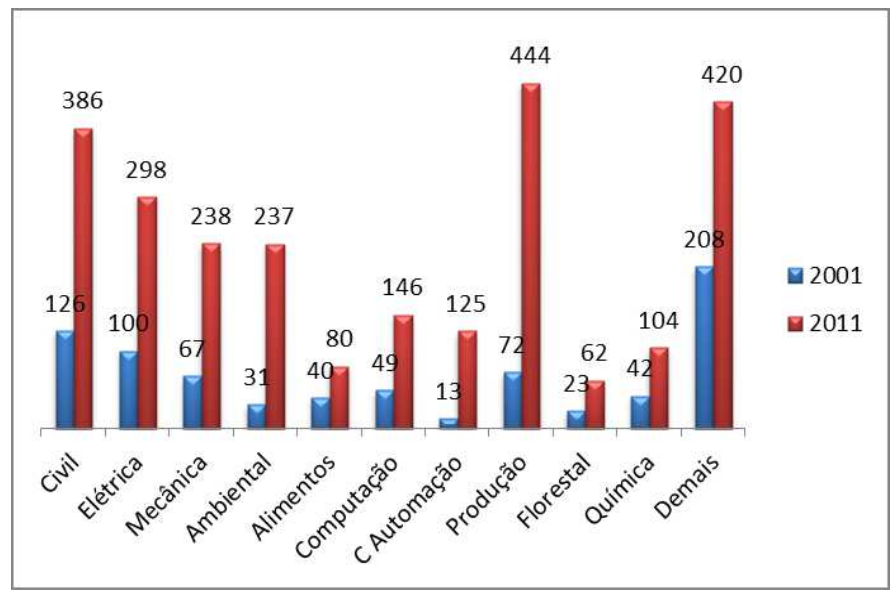

Fonte: Base de dados do Portal do INEP (2013).

\section{CONSIDERAÇÕES FINAIS}

Não é fácil saber qual caminho seguir depois de formado, nem a colocação do engenheiro perante o mercado de trabalho, mesmo estando com diploma em mãos e conhecimentos frescos, a concorrência é acirrada, as qualificações são amplas, os requisitos são rígidos e extensos.

De acordo com estudos feitos, entendeu-se que o primeiro passo a seguir depois de formado é dar prosseguimento nos investimentos em relação a aquilo que seu currículo de formação não tem como mínimo para uma qualificação em cargos de gestão, dentre esses diferenciais cita-se cursos de idioma, uma vez que foi possível verificar que. Um candidato à vaga pode ter mais êxito que outro, quando possui conhecimentos avançados em escrita, pronuncia e leitura na referida língua.

É necessário realizar cadastros em sites de Recursos Humanos tais como Catho, Manager, InfoJobs, dentre outros que firmam parceria com empresas que buscam profissionais para as vagas em aberto. Vale ressaltar que, é necessário que o candidato se mantenha atento ao seu perfil profissional e a vaga que pretende se candidatar, sendo necessárias novas qualificações para ser escolhido ao processo seletivo pretendido, caso seu currículo ainda não esteja de acordo com a descrição da vaga.

Nesse estudo também foi possível perceber que pouco valor se dá aos recém-formados no mercado, de imediato não costumam ser inseridos em sua área de formação, sendo submetidos a cargos inferiores como exemplos gerentes, supervisores o que pode durar um bom tempo, podendo chegar de 5 a 6 anos de espera. Esse fator ainda traz consigo a possibilidade de frustração uma vez que o retorno financeiro almejado após sua formação pode não acontecer, por diversos fatores, e também o retorno investido, caso o profissional tenha sido um aluno do ensino da rede particular, pode não ocorrer adequadamente, levando-se em conta o valor pago que é investido nas mensalidades da graduação.

De forma geral, conclui-se que o problema proposto nesse artigo foi atendido de forma 
parcial, uma vez que é difícil especificar com maior assertividade e sem tamanha generalidade quais passos um engenheiro recém-formado deve seguir para se colocar no mercado profissional. Não basta apenas serem formadas, as empresas exigem maiores e melhores qualificações a fim de terem excelentes profissionais em cargos ofertados, visando na hora da contratação experiências, o que torna o problema proposto subjetivo.

\section{REFERÊNCIAS}

Engenheiro de Produção. Disponível em: $<$ http://ultimosegundo.ig.com.br/educacao/guiade-profissoes/engenharia-deproducao/4edf7773fb3b72f05700001d.html>.

Acessado em: 26 de Março de 2014.

Engenharia de Produção. Disponível em: $<$ http://www.ucp.br/index.php/graduacao/cec/enge nharia/producao >. Acessado em: 28 de Março de 2014.

GIL, Antonio Carlos. Como elaborar Projetos de Pesquisa. Publicado em: São Paulo: Atlas. Paginas de 10 a 13.

IIDA, Itiro. Aplicações da Engenharia de Produção: estudo de sete casos em empresas brasileiras. Publicado em: São Paulo: Pioneira, 1972.

LESME, Adriano. Engenheiro de Produção. Disponível em: $<$ http://www.fea.usp.br/feaecon/econoteen/comocitar-a-bibliografia.php>. Acessado em: 24 de Março de 2014.

MIGUEL, Paulo Augusto Caucheck. Metodologia de Pesquisa em Engenharia de Produção e Gestão de Operações. Publicado em: Rio de Janeiro: Elsevier. 2010.
RIO, Puc. Perfil de engenheiro e da engenharia na visão do mercado de trabalho. Disponível em: $\quad\langle$ http://www.maxwell.lambda.ele.pucrio.br/11844/11844_6.PDF>. Acessado em: 27 de Março de 2014

VELLEI, Carolina. Gerente executivo da Volkswagen dá dicas sobre o curso e a carreira de Engenharia de Produção. Disponível em: $<$ http://guiadoestudante.abril.com.br/blogs/porden trodasprofissoes/gerente-executivo-davolkswagen-da-dicas-sobre-o-curso-e-a-carreirade-engenharia-de-producao/>. Acessado em: 26 de Março de 2014. 